\title{
Happy Birthday Albert Eschenmoser
}

\author{
Alan W. Schwartz ${ }^{1}$
}

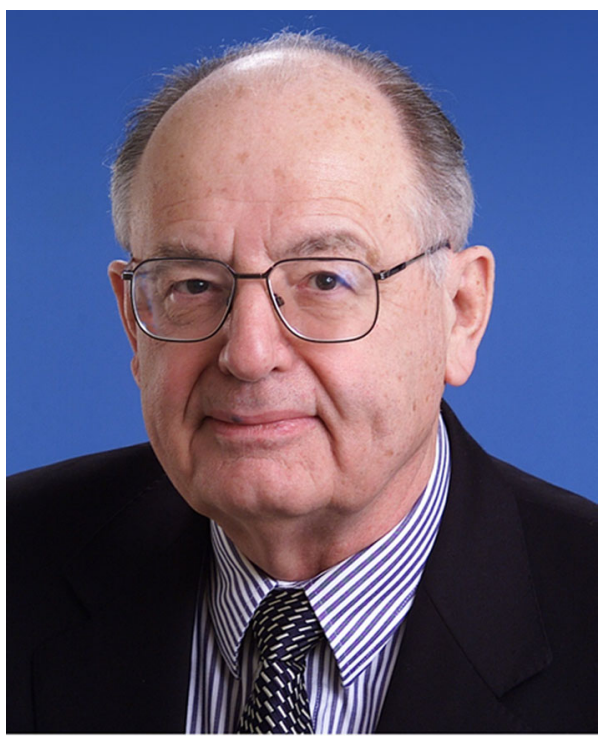

Albert Eschenmoser turned 90 in August of this year, an event that has been and will be celebrated in several publications. His career has spanned over sixty years and been characterized by what could be described as a kind of biomolecular prescience, or ability to identify and attack some of the central problems of organic chemistry and biochemistry. The origin of life community is probably most familiar with his question: "Warum Pentose- und nicht HexoseNucleinsäuren?" which was soon followed by a series of brilliant publications and an approach to what he termed the "Chemical Etiology of Nucleic Acid Structure." These studies have inspired many of us to attempt to follow his lead. In addition to a lengthy list of international

\section{Alan W. Schwartz}

originseditor@outlook.com 
awards and prizes, he was the recipient of ISSOL's 2002 Oparin medal. OLEB congratulates Professor Albert Eschenmoser on the occasion of his birthday and wishes him many more years of productive activity.

Alan W. Schwartz

(Photo courtesy of TSRI Biomedical Graphics) 